\title{
IS THE DORSAL PERCUTANEOUS APPROACH WELL-FOUNDED FOR OSTEOSYNTHESIS OF SCAPHOID FRACTURES?
}

\author{
Pavel Drac ${ }^{a *}$, Igor Cizmar ${ }^{a}$, Jan Hrbek ${ }^{b}$ \\ a Department of Traumatology, University Hospital Olomouc, Czech Republic \\ ${ }^{b}$ Clinic of Radiology, University Hospital Olomouc, Czech Republic
}

Received: February 9, 2009; Accepted: August 17, 2009

Key words: Scaphoid fractures/Limited dorsal approach/Dorsal percutaneous approach/Complications

Aims: To compare complications associated with dorsal percutaneous and limited dorsal approaches in the surgical treatment of fractured scaphoid bone.

Methods: A total of 51 patients with acute type A2, B2 and B3 scaphoid fractures were treated by limited dorsal approach. During follow-up examinations we analysed the functional outcome and per- and post-operative complications, and we compared them with studies using the dorsal percutaneous approach.

Results: We found fewer complications using the limited dorsal approach.

Conclusions: We found no advantages of the dorsal percutaneous approach. In addition to a favourable functional outcome, the limited dorsal approach permits visualization of the screw insertion point and of the fracture line course, and prevents insufficient screw sinking underneath the bone cartilage and malunion.

\section{INTRODUCTION}

Proximal pole fractures of the scaphoid bone as well as nondisplaced and minimally displaced fractures of the scaphoid waist can be treated using the dorsal approach. There is a tendency to perform these procedures using small surgical approaches within the context of mini-invasive surgery ${ }^{1}$. Some authors refer to a percutaneous screw insertion into the scaphoid bone from the dorsal aspect of the wrist. In contrast to a palmar percutaneous approach $^{2}$. However, there are tendon and nerve structures between the skin and the proximal scaphoid bone pole. These structures are at risk of injury, as a cadaver study shows $^{3}$. We use the so-called limited dorsal approach for the screw insertion into the proximal pole of the scaphoid bone $e^{4}$ rather than a percutaneous approach. That enabled us to visualize the tendons, nerves and screw entry point. In the patient group treated with the above-mentioned technique, we analyzed the frequency and pattern of complications and compared them with studies using a dorsal percutaneous approach.

\section{MATERIALS AND METHODS}

From October 2003 to March 2008 a total of 51 patients with acute scaphoid fracture (type A2, B2 and B3 according to Herbert's classification ${ }^{5}$ ) were treated by the limited dorsal approach at the Department of Traumatology, University Hospital Olomouc. There were 44 patients who underwent clinical and radiographic follow-up examinations after a minimum period of 12 months. The average age of the group consisting of $5 \mathrm{fe}$ males and 39 males was 25.9 years ( 16 to 57 years of age), with an average follow-up of 23.9 months (12 to 36 months). Nine fractures (20.5\%) were type A2, 31
(70.5 \%) type B2 and 4 (9.1\%) type B3. All the surgeries were performed under general anaesthesia or using the supraclavicular block, and a pneumatic tourniquet was applied to the upper arm. The standard and cannulated versions of the HBS-mini headless bone screw were used. During the follow-up examinations we investigated any resting pain, pain on movement, range of motion, and grip strength compared with the opposite, unaffected wrist. Pre-and post-operavtive complications were also followed.

\section{RESULTS}

Table 1 shows the functional outcome. Table 2 shows the frequency of particular complications during check-up examinations compared to the results of Bushnell et al. ${ }^{11}$. Guidewire bending during surgery was found three times in our patient group. There was no infection found postooperatively. Nevertheless, one patient described hypersthesia in a $2 \times 3 \mathrm{~cm}$ area near the distal end of the wound, and another patient mentioned paresthesia in the same region. Both complaints subsided spontaneously. We found one symptomatic scaphoid nonunion with degenerative changes (SNAC II). This patient did not come for any check-up after the surgery until over a year later. We performed proximal row carpectomy and his complaints subsided in part. X-ray and CT-examinations revealed no degenerative changes in the remaining 43 patients.

\section{DISCUSSION}

A dorsal approach to the scaphoid bone is used for the treatment of mainly the fractures and nonunions of the proximal pole ${ }^{6}$. Anatomic and experimental studies ${ }^{2,7}$ report a more accurate and reliable central axis screw 
Table 1. Functional outcome during follow-up examination. Flexion, extension, radial and ulnar deviation and grip strength compared with the opposite, unafected wrist.

\begin{tabular}{|l|c|}
\hline & $\mathrm{n}=44$ \\
\hline Free of persistent complaints & $35(79.5 \%)$ \\
\hline Resting pain & $1(2.3 \%)$ \\
\hline Pain during activities & $8(18.2 \%)$ \\
\hline Flexion & $90.1 \%$ \\
\hline Extension & $91.7 \%$ \\
\hline Radial deviation & $90.3 \%$ \\
\hline Ulnar deviation & $95.8 \%$ \\
\hline Grip strength & $92.1 \%$ \\
\hline
\end{tabular}

Table 2. Comparison of complications in this study and the study of Bushnell et al. ${ }^{11}$

\begin{tabular}{|l|c|c|}
\hline & Our results & Ref. $^{11}$ \\
\hline Patients & $\mathrm{n}=44$ & $\mathrm{~N}=24$ \\
\hline Skin incision & $2-3 \mathrm{~cm}$ & percutaneous \\
\hline Fracture pattern & $\mathrm{A} 2, \mathrm{~B} 2, \mathrm{~B} 3$ & $\mathrm{~A} 2, \mathrm{~B} 2$ \\
\hline \multicolumn{3}{|c|}{} \\
\hline $\begin{array}{l}\text { Guidewire bending / } \\
\text { breakage }\end{array}$ & $3(6.8 \%)$ & $1(4.2 \%)$ \\
\hline Screw breakage & 0 & $1(4.5 \%)$ \\
\hline Wound infection & 0 & 0 \\
\hline Hypo- paresthesia & $2(4.5 \%)$ & 0 \\
\hline $\begin{array}{l}\text { Total minor compli- } \\
\text { cations }\end{array}$ & $5(11.4 \%)$ & $2(8.3 \%)$ \\
\hline \multicolumn{2}{|c|}{} & $1(4.2 \%)$ \\
\hline Nonunion & $1(2.3 \%)$ & $3(12.5 \%)$ \\
\hline $\begin{array}{l}\text { Screw protrusion or } \\
\text { malposition }\end{array}$ & 0 & $1(4.2 \%)$ \\
\hline $\begin{array}{l}\text { Fracture close to } \\
\text { screw insertion } \\
\text { point }\end{array}$ & 0 & $5(20.8 \%)$ \\
\hline $\begin{array}{l}\text { Total major compli- } \\
\text { cations }\end{array}$ & $1(2.3 \%)$ \\
\hline \multicolumn{2}{|c|}{$0(13.6 \%)$} & $7(29.2 \%)$ \\
\hline Total complications & 6 & \\
\hline
\end{tabular}

placement with the dorsal approach versus the palmar approach in nondisplaced or minimally displaced scaphoid fractures. Central screw position creates greater stiffness and leads to failure ${ }^{8}$. A 2008 anatomic study by Adamani et al. ${ }^{3}$ showed high risk of tendon and nerve damage with the percutaneous fixation of the scaphoid through a dorsal approach. In $58 \%$ of wrist cadavers they found the guidewire going through the extensor pollicis longus tendon or extensor indicis proprius tendon or extensor digitorum communis to the index, and in $42 \%$ the guide wire passed through the terminal portion of the posterior interosseous nerve. For this reason, we use the so-called limited dorsal approach with a 2 to $3 \mathrm{~cm}$ skin incision that permits the retraction of the above-mentioned tendons to the border of the field of operation and, in addition, visualization of the screw insertion point. Only this enables the screw to be sunk underneath the bone cartilage to prevent distal radius cartilage irritation in case of screw protrusion $^{9}$. The functional outcome (see Table 1) is fully comparable to the published studies ${ }^{9,10}$. The only study that analyses in detail complications in patients treated for scaphoid fracture using a dorsal percutaneous approach is the work by Bushnell et al. ${ }^{11}$, which, unfortunately, does not analyze the functional outcome. The above-mentioned authors divide complications into minor, i.e. those that require an additional nonsurgical intervention (deviation from the standard surgical technique, prolonged time of surgery, superficial infection or prolonged wound drainage up to five days, transient neurologic symptoms, stiffness or tendon irritation) and major complications, which include complications resulting in the need for additional surgical intervention (nonunion, malunion, fracture, compartment syndrome, permanent nerve injury, septic arthritis, vascular injury, complex regional pain syndrome, permanent stiffness or tendon rupture). These authors report two cases of screw protrusion above the scaphoid cartilage and one case of fracture malposition (12.5\% in total).Using this percutaneous approach the surgeon is fully dependent on fluoroscopy without being able to observe the screw sinking and fracture reduction with his own eyes. Using a limited dorsal approach the proximal scaphoid pole is clearly visible and the sinking of the screw underneath the bone cartilage can be subsequently checked. After a slight dorsiflexion, the surgeon can also see the result of fracture reduction. Like Bushnell et al. ${ }^{11}$, we observed no injury to tendons such as the extensor pollicis longus, extensor indicis or extensor digitorum communis for the index finger in our study.

\section{CONCLUSION}

We found no advantages of a dorsal percutaneous approach for the operative treatment of type A2, B2 and B3 scaphoid fractures. Along with its favourable functional outcome, the limited dorsal approach permits visualization of the screw insertion point and of the fracture line course, and prevents insufficient screw sinking underneath the bone cartilage and malunion.

\section{ACKNOWLEDGMENTS}

This article is supported by grant project IGA MZČR NS 9623-4/2008. 


\section{REFERENCES}

1. Pilný J. Přínos artroskopie $\mathrm{k}$ diagnostice a terapii obtíží v oblasti zápěstí. Acta Chir. Orthop. Traum čech 2004; 71:106-109.

2. Kamineni S, Lavy CB. Percutaneous fixation of scaphoid fractures. An anatomical study. J Hand Surg 1999; 24B:85-88.

3. Adamani DC, Mikola EA, Fraser BJ. Percutaneous fixation of the scaphoid through a dorsal approach: an anatomic study. J Hand Surg 2008; 33A:327-331.

4. Dráč P. Osteosyntéza zlomenin člunkové kosti z limitovaného dorzálního př́stupu. Úraz chir 2006; 14:103-108.

5. Herbert TJ.The fractured scaphoid. St Louis: Quality Medical Publishing, Inc; 1990.

6. DeMaag RL, ENGBER WD. Retrograde Herbert screw fixation for treatment of proximal pole scaphoid nonunions. J Hand Surg 1989; 14A:996-1003.
7. Chan KW, McAdams TR. Central screw placement in percutaneous screw scaphoid fixation: a cadaveric comparision of proximal and distal techniques. J Hand Surg 2004; 29A:74-79.

8. McCallister WV, Knight J, Kaliappan R, Trumble TE. Central placement of the screw in simulated fractures of the scaphoid waist: a biomechanical study. J Bone Joint Surg 2003; 85A:72-77.

9. Bedi A, Jebson PJL, Hayden RJ, Jacobson JA, Martus JE.Internal fixation of acute, nondisplaced scaphoid waist fracture via a limited dorsal approach: an assessment of radiographic and functional outcomes. J Hand Surg 2007; 32A:326-333.

10. Slade ${ }^{3 r d}$ JF, Gutow, AP, Geissler, WB. Percutaneous internal fixation of scaphoid fractures via an arthroscopically assisted dorsal approach. J Bone Joint Surg 2002; 84A, Suppl 2:21-36.

11. Bushnell BD, McWilliams AD, Messer TM.Complications in dorsal percutaneous cannulated screw fixation of nondisplaced scaphoid waist fracture. J Hand Surg 2007; 32A:827-833. 
